\title{
Ultrasound-Guided Transversus Abdominis Plane Block for Cesarean Delivery: Injection Site Pain as a New Complication and Dexamethasone Reduced Incidence
}

\author{
Hai-Lin Liu',* \\ Rui-Hao Zhou $\mathbb{D}^{2, *}$ \\ Li-Li Luo' \\ Xue Yuan' \\ Ling $Y e$ (ID) $^{2}$ \\ He-Guo Luo' \\ 'Department of Anesthesiology, The \\ Third Affiliated Hospital of Nanchang \\ University, Nanchang, Jiangxi 330008, \\ People's Republic of China; ${ }^{2}$ Department \\ of Pain Management, West China \\ Hospital, Sichuan University, Chengdu, \\ Sichuan 61004I, People's Republic of \\ China \\ *These authors contributed equally to \\ this work
}

This article was published in the following Dove Press journal:

Journal of Pain Research

Background: Although ultrasound-guided transversus abdominis plane block (TAPB) is widely used in multimodal analgesia after cesarean delivery (CD), the complications of TAPB during analgesia after CD have rarely been reported.

Methods: A total of 84 cases of $\mathrm{CD}$ were randomly assigned to either a ropivacaine group ( $\mathrm{R}$ group) or ropivacaine + dexamethasone group ( $\mathrm{RD}$ group) in this double-blind trial. The pain site and pain degree at rest and during activity at $2 \mathrm{~h}, 6 \mathrm{~h}, 10 \mathrm{~h}, 12 \mathrm{~h}, 14 \mathrm{~h}, 16 \mathrm{~h}, 20 \mathrm{~h}$, and $24 \mathrm{~h}$ after maternal surgery were recorded. The consumption of opioids at $24 \mathrm{~h}$, postoperative nausea, vomiting, exhaustion, and other adverse reactions were recorded.

Results: A total of 80 patients were included in the analysis of results. A total of 19 patients developed ISP, 14 in the R group and 5 in the RD group. The incidence of ISP in the R and RD groups was $35 \%$ and $12.5 \%$, respectively. The results described above showed that combining dexamethasone with ropivacaine reduced the incidence of ISP, and the difference was statistically significant $(\mathrm{P}<0.05)$. Two groups of women with positive ISP had higher values of opioid consumption than women with negative ISP, but the difference was not significant.

Conclusion: Dexamethasone as an adjuvant for ropivacaine can effectively relieve the ISP of ultrasound-guided TAPB after CD, and can enhance the analgesic effect of ropivacaine.

Keywords: dexamethasone, ropivacaine, cesarean delivery, transversus abdominis plane block, postoperative analgesia, injection site pain

\section{Introduction}

Labor pain is considered to be the most severe pain experienced by women worldwide. ${ }^{1}$ Increasing evidence shows that severe labor pain, especially after $\mathrm{CD}$, may result in the development of chronic post-surgical pain (CPSP) and postpartum depression. ${ }^{2}$ However, the management of analgesia after CD is still not satisfactory. It is recognized that the most effective way to reduce pain after CD is via epidural opioids. However, some experts believe that epidural administration of opioids is no longer the best method for postoperative analgesia due to the side effects of respiratory depression, postoperative mobility, low back pain, nausea, vomiting, weakened bowel motility, and other adverse reactions. ${ }^{3,4}$ Compared with traditional intravenous self-controlled analgesia, multimodal analgesia has become the mainstay for postoperative analgesia.
Correspondence: He-Guo Luo

Department of Anesthesiology, The Third Affiliated Hospital of Nanchang

University, Nanchang, Jiangxi 330008,

People's Republic of China

Email542534631@qq.com 
Ultrasound-guided TAPB is an effective analgesic method that provides good analgesia during lower abdominal surgery. ${ }^{5,6}$ In 2009, Belavy et al first used ultrasound-guided TAPB for analgesia after $\mathrm{CD}$ and achieved satisfactory results. ${ }^{7}$ Ultrasound-guided TAPB has become increasingly widely used for postoperative analgesia after $\mathrm{CD}$. However, complications of ultrasound-guided TAPB after CD have rarely been reported. Only two cases of local anesthetic toxicity were reported in $2013^{8,9}$ and 2014. ${ }^{10-12}$

The incidence of ISP by ultrasound-guided TAPB after $\mathrm{CD}$ has not been reported. In daily work, we found that some women with CD had postoperative ISP after ultrasoundguided TAPB. Mild ISP affects maternal comfort and increase the maternal psychological burden, while severe ISP affects maternal sleep and rollover, cause maternal anxiety and depression, and may even cause CPSP. ${ }^{13}$ Although ultrasound-guided TAPB improves the (visual analog scale) VAS score in terms of the abdominal surgical incision during the local anesthetic efficacy period and improves the analgesic satisfaction, the ISP still causes considerable trouble for patients. Dexamethasone is an effective and highly selective glucocorticoid, that is widely used as an adjuvant for various local anesthetics (LAs) involved in nerve blocks; dexamethasone can prolong the block time and enhance the analgesic effect. ${ }^{14-16}$ It is also used as a neuroprotective agent because of its anti-inflammatory and immunosuppressive effects. ${ }^{17,18}$ The purpose of our research was to observe the incidence of ISP via ultrasound-guided TAPB for analgesia after $\mathrm{CD}$ and the effect of additional dexamethasone combined with ropivacaine on ISP.

\section{Methods}

\section{Study Subjects and Groups}

The procedure used in the study was explained to the mothers before surgery, and they were included in the study after written informed consent was obtained. The study was conducted in accordance with the Declaration of Helsinki, and the protocol was approved by the Ethics Committee of the Third Affiliated Hospital of Nanchang University (Ethical batch number:FB2019001). Eightyfour women admitted to the Third Affiliated Hospital of Nanchang University from January 2019 to April 2019 for $\mathrm{CD}$ were randomly divided into the $\mathrm{R}$ group and $\mathrm{RD}$ group according to a computer-generated random number table, the patient characteristics were as follows: classified as ASA I-II, 22-42 years old, $155-170 \mathrm{~cm}, 55-100 \mathrm{~kg}$. The exclusion criteria were patients who had a history of abdominal surgery other than $\mathrm{CD}$; and those with a history of severe systemic diseases, opioid abuse or allergies, severe pregnancy complications (such as severe intrahepatic cholestasis), and mental illness.

\section{Method Selection}

All participants received spinal anesthesia for $\mathrm{CD}$. The patient was placed in the left lateral position and administered anL2-L3 gap puncture with $15 \mathrm{mg}$ of $0.5 \%$ ropivacaine hydrochloride (NAROPIN $1.0 \%(100 \mathrm{mg} / 10 \mathrm{~mL})$ AstraZeneca) in the subarachnoid space, and the anesthesia plane was T4-T6 before the incision. No drugs were added to the epidural. All the patients were given 20 $\mathrm{U}$ oxytocin during the operation, and the usual intravenous infusion of $20 \mathrm{U}$ was administered. After the surgery, a venous analgesia pump was connected. The analgesic drug formula was tonoforphan tartaric acid $(8 \mathrm{mg})+$ dextrozine injection $(10 \mathrm{mg})+$ dexmedetomidine hydrochloride $(200 \mu \mathrm{g})$, diluted to $100 \mathrm{~mL}$ with $0.9 \%$ sodium chloride solution. The background dose was $2 \mathrm{~mL} / \mathrm{h}$, the self-controlled analgesic pump dose was $2 \mathrm{~mL}$ one time, and the locking time was 20 mins.

After $\mathrm{CD}$, the patients were sent to the post-anesthesia care unit (PACU) and underwent ultrasound-guided TAPB performed by the anesthetist. The specific operation was as follows: the patient was placed in a supine position, the lateral abdominal area was exposed between the bilateral ribs and the iliac crest, and after disinfecting the skin, a linear high-frequency ultrasound probe $(6-12 \mathrm{MHz}$, Visonic Shenzhen China) was placed transversely on the anterolateral abdominal wall between the iliac crest and the costal margin. Under ultrasound guidance, three layers of muscles - the external oblique, internal oblique, and transversus abdominis - were identified (Figure 1). The needle was inserted into the fascia between the oblique abdominal muscle and the transversus abdominis muscle, and no blood was pumped back. A test dose of $1 \mathrm{~mL}$ was used to determine the position of the needle tip. The operator and the assistant jointly assessed the position of the needle tip and whether the pressure was satisfactory and then fixed the position of the needle tip. Patients in the $\mathrm{R}$ group were injected with a total of $20 \mathrm{~mL}$ of $0.25 \%$ ropivacaine hydrochloride, and patients in the $\mathrm{RD}$ group were injected with $20 \mathrm{~mL}$ of $0.25 \%$ ropivacaine + dexamethasone $(5 \mathrm{mg})$. On the ultrasound image, the fascial layer between the intra-abdominal oblique muscle and the transversus abdominis muscle was torn apart by local anesthetic to form a hypoechoic fusiform image (Figure 1). After the injection, it skin was disinfected again, and a sterile 


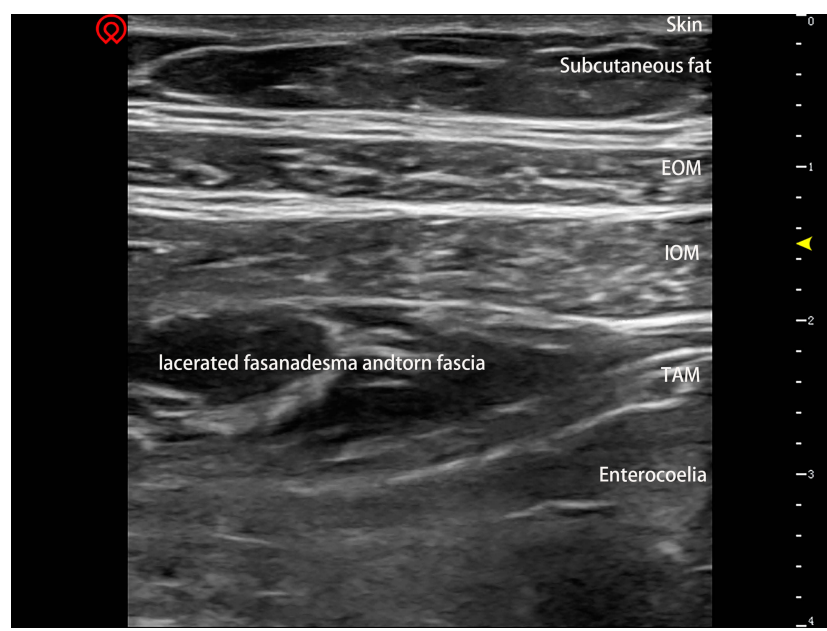

Figure I Fusiform shadow under ultrasound: three layers of muscles-external oblique muscle (EOM); internal oblique muscle (IOM); transverse abdominis muscle (TAM). The red symbol is the maker of the ultrasonic probe, indicating the position and direction of the ultrasonic probe. The yellow arrow indicates a depth of $1.5 \mathrm{~cm}$ from the skin.

dressing was applied. The same method performed for the TAPB was performed on the other side. The local anesthetic administered to the mother was prepared by an anesthesiologist who assigned a randomized group. The TAPB procedure was performed by another experienced anesthesiologist and assisted by an anesthesia resident physician. After TAPB, the patient was observed for 10 mins, and was confirmed to have no discomfort and returned to the ward. The information was returned by those who did not participate in randomization and TAPB. After explaining the VAS procedure to the patient, the nighttime VAS score was recorded by the patient in the score sheet.

\section{Observation and Evaluation}

The time point of the ultrasound-guided TAPB was recorded as $0 \mathrm{~h}$ after surgery. We mainly observed the ISP, pain onset time, and initial VAS score. ISP judgment method: When assessing VAS scores, the specific site of pain was pointed out by the parturient. When the parturient indicated pain at the injection site, the parturient remained calm in a supine position, and the anesthesiologist gently touched the injection site to clarify the nature of the injection site and the real existence of pain. The resting pain scores of the surgical incisions were recorded at $2 \mathrm{~h}, 6$ h, $10 \mathrm{~h}, 12 \mathrm{~h}, 14 \mathrm{~h}, 16 \mathrm{~h}, 20 \mathrm{~h}$, and $24 \mathrm{~h}$. The secondary objective was to observe the total number of compressions of the $24 \mathrm{~h}$ analgesia pump and whether it was exhausted, and adverse reactions such as nausea, vomiting, and drowsiness were assessed after $24 \mathrm{hrs}$.

\section{Statistical Analysis}

Data were analyzed using the statistical software SPSS Statistics 24 (IBM SPSS, New York, USA). Continuous variables were analyzed by independent Student's $t$-test. The cardiac test or Fisher's exact test was used to analyze the injection site pain, anal exsufflation, nausea, and vomiting. The data were expressed as the mean \pm standard deviation (SD). $\mathrm{P}<0.05$ was considered statistically significant for the twosided test.

\section{Results}

As shown in Figure 2, 84 randomly selected women with CD were divided into the $\mathrm{R}$ group (42 cases) and $\mathrm{RD}$ group (42 cases). Finally, 2 cases in each group were excluded. One patient in the $\mathrm{R}$ group discontinued the intravenous analgesia pump after $4 \mathrm{~h}$, and the other patient in the $\mathrm{R}$ group refused to return because of the unbearable pain and poor mental state. Two women in the RD group were transferred to the Obstetric ICU due to a large amount of bleeding (intraoperative blood loss: $1000 \mathrm{~mL}$ in 1 case and $1200 \mathrm{~mL}$ in 1 case) during the operation and the potential postoperative bleeding risk. Finally, data from 80 patients were available for further analysis ( $\mathrm{R}=40 ; \mathrm{RD} n=40$, Figure 2).

\section{General Condition}

As shown in Table 1, the basic information of the 80 patients, which included the age, height, weight, operative time, and ASA grading statistical data (mean $\pm \mathrm{SD}$ ) were not significantly different.

\section{ISP Occurrence and Start Time After TAPB}

According to the description of the method, the VAS score was recorded by the mother at each time period, and the pain site was described. When the mother indicated significant pain at the puncture site, the anesthesiologist confirmed the presence of pain that was different from pain at the surgical incision site, the mother was considered to be ISP positive. As shown in Tables 2 and 3, we collected the time point at which patients experienced ISP and the VAS score through the return visit and self-assessment records. In 80 cases, 19 women had ISP, 14 cases in the $\mathrm{R}$ group and 5 cases in the RD group. The difference was statistically significant $(\mathrm{P}<0.05)$. As mentioned by patients, the ISP was described as soreness, and the site was the position of the TAPB local anesthetic injection. Unlike the paroxysmal sensation produced by contractions, the ISP persisted after the pain occurred and was aggravated when the 


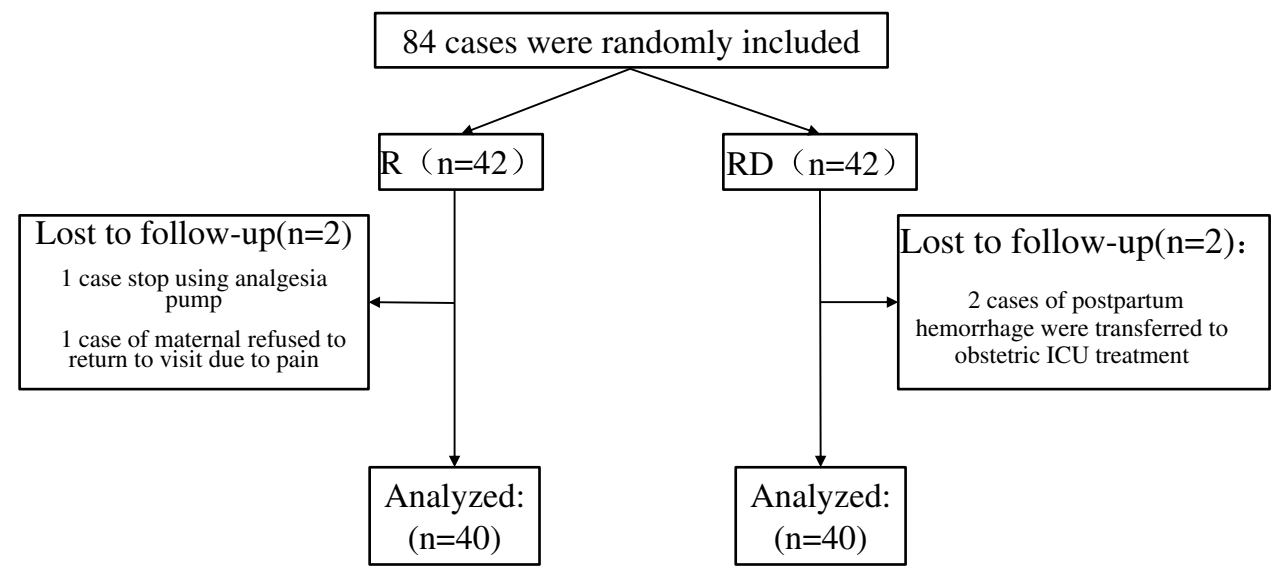

Figure 2 Randomization flowchart.

inject site was lightly pressed and when patients turned over. According to maternal responses, mild ISP reduces comfortable feelings, and pain in many locations causes maternal anxiety regarding postoperative recovery; Severe ISP affects maternal sleep and turning over, result in severe physical pain and mental anxiety in mothers, and affects the postoperative recovery of patients. Three cases of ISP-positive women occasionally had a unilateral tingling sensation when turning over,

Table I Comparison of General Information Between the Two Groups (Mean+SD)

\begin{tabular}{|l|l|l|l|}
\hline & $\mathbf{R}(\mathbf{n}=\mathbf{4 0})$ & $\mathbf{R D}(\mathbf{n}=\mathbf{4 0})$ & $\mathbf{P}$ \\
\hline Age (years) & $29.675 \pm 5.025$ & $29.1 \pm 4.808$ & 0.603 \\
Height (cm) & $159.65 \pm 3.076$ & $160.25 \pm 3.636$ & 0.428 \\
Weight (kg) & $71.475 \pm 9.785$ & $69.625 \pm 9.203$ & 0.386 \\
Operation time (min) & $61.375 \pm 20.096$ & $60.75 \pm 26.422$ & 0.906 \\
\hline ASA PS & & & \\
I & $15(37.5 \%)$ & $17(42.5 \%)$ & $>0.05$ \\
II & $25(62.5 \%)$ & $23(57.5 \%)$ & \\
\hline
\end{tabular}

Abbreviation: SD, Standard deviation.

Table 2 The Occurrence of ISP After TAPB

\begin{tabular}{|l|l|l|l|}
\hline & R & RD & P \\
\hline Total number of cases & 14 & 5 & 0.025 \\
Painful nature & & & \\
Mild soreness & 12 & 5 & \\
Severe pain & 2 & 0 & \\
Sustained after pain & & & \\
The number of cases of persistent pain & 12 & 4 & \\
Number of pains only during activity & 2 & 1 & \\
Touching, turning over will aggravating pain & Yes & Yes & \\
Acupuncture feeling during activity & 3 & 0 & \\
Injection site touch hard & 1 & 0 & \\
\hline
\end{tabular}

and there was no tingling sensation when lying down. The nerve-tingling sensation might be related to nerve damage. In the case where the spinal anesthesia effect still existed, even if there was a premeasurement and if a suitable injection pressure was found, the ultrasound image cannot show nerves, so damage caused by the needle cannot be avoided.

In the R group, in 12 patients of 14 ISP-positive cases, the ISP continued to exist after the pain appeared. In addition, two of 14 patients reported distinct soreness when turning over or during pressure, and the soreness disappeared after tens of minutes maintained in a fixed body position such as during bed rest. In the RD group, 4 ISP-positive women had persistent pain. One of 4 patients experienced obvious pain when turning over, which disappeared after being in bed. One of the

Table 3 The Onset Time (Postoperative) and Initial VAS of ISP

\begin{tabular}{|c|c|c|c|c|c|c|}
\hline \multirow{3}{*}{$\begin{array}{l}\text { Number } \\
\text { of Cases }\end{array}$} & \multicolumn{3}{|l|}{$\mathbf{R}$} & \multicolumn{3}{|l|}{ RD } \\
\hline & \multirow{2}{*}{$\begin{array}{l}\text { Start } \\
\text { Time }\end{array}$} & \multicolumn{2}{|l|}{ VAS } & \multirow{2}{*}{$\begin{array}{l}\text { Start } \\
\text { Time }\end{array}$} & \multicolumn{2}{|l|}{ VAS } \\
\hline & & Rest & Activity & & Rest & Activity \\
\hline 1 & $14 \mathrm{~h}$ & 2 & $\begin{array}{l}\text { Left:3 and } \\
\text { right:5 }\end{array}$ & $14 \mathrm{~h}$ & 0 & 1 \\
\hline 2 & $16 \mathrm{~h}$ & 2 & 5 & $20 \mathrm{~h}$ & 1 & 2 \\
\hline 3 & $16 \mathrm{~h}$ & 3 & 4 & $16 \mathrm{~h}$ & 2 & 3 \\
\hline 4 & $10 \mathrm{~h}$ & 1 & 2 & $20 \mathrm{~h}$ & 1 & 2 \\
\hline 5 & $20 \mathrm{~h}$ & 1 & 2 & $20 \mathrm{~h}$ & 1 & 2 \\
\hline 6 & $15 \mathrm{~h}$ & 1 & 2 & & & \\
\hline 7 & $14 \mathrm{~h}$ & 2 & 3 & & & \\
\hline 8 & $20 \mathrm{~h}$ & 1 & 2 & & & \\
\hline 9 & $12 \mathrm{~h}$ & 1 & 2 & & & \\
\hline 10 & $16 \mathrm{~h}$ & 0 & 2 & & & \\
\hline 11 & $16 \mathrm{~h}$ & 0 & 2 & & & \\
\hline 12 & $20 \mathrm{~h}$ & 2 & 5 & & & \\
\hline 13 & $16 \mathrm{~h}$ & 1 & 3 & & & \\
\hline 14 & $20 \mathrm{~h}$ & 1 & 2 & & & \\
\hline
\end{tabular}


Table 4 The Opioid Demand of ISP-Positive and ISP-Negative Patients (Mean+SD)

\begin{tabular}{|l|l|l|l|}
\hline Group & Positive & Negative & $\mathbf{P}$ \\
\hline R & $5.071 \pm 7.436$ & $3.615 \pm 5.201$ & 0.473 \\
RD & $2.200 \pm 2.168$ & $1.257 \pm 1.421$ & 0.473 \\
\hline
\end{tabular}

Abbreviation: SD, Standard deviation.

ISP-positive women in the R group experienced intense pressure on the right injection side $16 \mathrm{hrs}$ after surgery. The pain was aggravated with pressure, and the intense feeling disappeared $24 \mathrm{hrs}$ after surgery, but the pain persisted. Within $24 \mathrm{hrs}$ of observation, the ISP appeared after the local anesthetic effect was reduced, and it first appeared $10 \mathrm{hrs}$ after surgery and, at the latest, $20 \mathrm{hrs}$ after surgery. Unfortunately, we did not obtain the pain scores at all time points in ISPpositive patients. The decrease in the local anesthetic effect via TAPB aggravated the degree of pain at the operation site. In addition, the obstetrician encouraged patients to perform a half-hour turn over and get out of bed as early as possible in the days postoperatively. Activity and standing aggravated the extent and the range of pain. Pain at the injection site and pain in the surgical incision affect each other, although the patient was able to determine that the pain at the injection site and the pain in the surgical incision were pain at both sites, most patients were unable to distinguish the inject pain scores from the surgical incision pain scores. Therefore, we did not analyze the VAS score data after the ISP occurred.

\section{The Number of Analgesic Pump Presses in the ISP-Positive and ISP-Negative Groups}

As shown in Table 4, we used the number of analgesic pump presses to indicate the increased demand for opioids. In this observation, the ISP-positive women had a higher mean value of presses than the ISP-negative women, but the difference was not statistically significant.

\section{Resting VAS Scores for Surgical Incision Pain in the ISP-Positive and ISP-Negative Groups}

As show in Table 5, within $24 \mathrm{~h}$ of observation, there was no significant difference in the resting VAS scores regarding the surgical incision between ISP-positive and ISP-negative women in both the $\mathrm{R}$ group and $\mathrm{RD}$ group. In addition, there were no significant differences in resting VAS scores between ISP-positive $(\mathrm{n}=19)$ and ISP-negative women $(n=61)$. ISP might cause more severe surgical incision pain, but there was no significant difference in the first $24 \mathrm{hrs}$.

\section{Resting VAS Scores for Surgical Incision Pain Between the R Group and RD Group}

Table 6 shows that the resting VAS scores of the RD group were lower than those of the R group $2 \mathrm{~h}, 10 \mathrm{~h}, 12 \mathrm{~h}, 14 \mathrm{~h}$, and $16 \mathrm{~h}$ after surgery $(\mathrm{P}<0.05)$. The data showed that dexamethasone as an adjuvant of $0.25 \%$ ropivacaine hydrochloride could prolong the duration of action of ropivacaine and enhance its analgesic effect.

\section{The Number of Intravenous Analgesia Administration Within $24 \mathrm{hrs}$ in the $R$ and RD Groups}

According to the number of compressions recorded from the analgesic pump (Table 7), the number of analgesic pump presses in the $\mathrm{RD}$ group compared with the $\mathrm{R}$ group was significantly reduced within $24 \mathrm{hrs}(\mathrm{P}<0.05)$, and the

Table 5 Resting VAS Score of Surgical Incision in the ISP-Positive Group and ISP-Negative Group (Mean+SD)

\begin{tabular}{|c|c|c|c|c|c|c|c|c|c|}
\hline \multirow[t]{2}{*}{ Duration (h) } & \multicolumn{3}{|l|}{ Group R } & \multicolumn{3}{|c|}{ Group RD } & \multicolumn{3}{|c|}{ Group R+RD } \\
\hline & Positive & Negative & $\mathbf{P}$ & Positive & Negative & $\mathbf{P}$ & Positive & Negative & $\mathbf{P}$ \\
\hline 2 & $0.857 \pm 0.949$ & $1.269 \pm 0.604$ & 0.158 & $0.4 \pm 0.894$ & $0.77 I \pm 0.770$ & 0.328 & $0.737 \pm 0.933$ & $0.984 \pm 0.74 \mid$ & 0.302 \\
\hline 6 & $2.07 I \pm 1.269$ & $1.615 \pm 0.496$ & 0.215 & $1.6 \pm 0.548$ & $1.514 \pm 0.562$ & 0.751 & $1.947 \pm 1.129$ & $1.557 \pm 0.533$ & 0.161 \\
\hline 10 & $2.929 \pm 1.685$ & $2.769 \pm 1.210$ & 0.757 & $2.2 \pm 1.095$ & $1.857 \pm 0.733$ & 0.363 & $2.737 \pm 1.558$ & $2.246 \pm 1.059$ & 0.212 \\
\hline 12 & $3.357 \pm 1.447$ & $3.423 \pm 1.206$ & 0.879 & $2.6 \pm 1.346$ & $2.2 \pm 0.933$ & $0.40 \mathrm{I}$ & $2.737 \pm 1.558$ & $2.721 \pm 1.213$ & 0.964 \\
\hline 14 & $3.57 I \pm 1.284$ & $3.654 \pm 1.056$ & 0.828 & $3.2 \pm 1.095$ & $2.629 \pm 1.215$ & 0.327 & $3.474 \pm 1.219$ & $3.066 \pm 1.250$ & 0.215 \\
\hline 16 & $3.429 \pm 1.284$ & $3.654 \pm 0.936$ & 0.528 & $3 \pm 1.000$ & $3.057 \pm 1.110$ & 0.914 & $3.316 \pm 1.204$ & $3.311 \pm 1.073$ & 0.988 \\
\hline 20 & $3.143 \pm 1.099$ & $3.23 I \pm 0.765$ & 0.768 & $3.4 \pm 0.548$ & $3.4 \pm 0.946$ & I & $3.211 \pm 0.976$ & $3.328 \pm 0.870$ & 0.619 \\
\hline 24 & $3.143 \pm 0.949$ & $3.038 \pm 0.662$ & 0.686 & $3.4 \pm 0.548$ & $3.257 \pm 0.886$ & 0.729 & $3.211 \pm 0.855$ & $3.164 \pm 0.780$ & 0.828 \\
\hline
\end{tabular}

Abbreviation: SD, Standard deviation. 
Table 6 Resting VAS Scores of Surgical Incisions at Various Time Points After Surgery (Mean+SD)

\begin{tabular}{|l|l|l|l|l|l|}
\hline \multirow{2}{*}{$\begin{array}{l}\text { Duration } \\
\text { (h) }\end{array}$} & \multicolumn{2}{|l|}{ Group } & \multicolumn{2}{l|}{$\mathbf{9 5 \%} \mathbf{C l}$} & $\mathbf{P}$ \\
\cline { 2 - 6 } & GroupRD & GroupR & $\begin{array}{l}\text { Lower } \\
\text { Limit }\end{array}$ & $\begin{array}{l}\text { Upper } \\
\text { Limit }\end{array}$ & \\
\hline 2 & $0.725 \pm 0.784$ & $1.125 \pm 0.757$ & -0.743 & -0.057 & 0.023 \\
6 & $1.525 \pm 0.554$ & $1.775 \pm 0.862$ & -0.573 & 0.073 & 0.127 \\
10 & $1.9 \pm 0.778$ & $2.825 \pm 1.375$ & -1.422 & -0.428 & 0.000 \\
12 & $2.25 \pm 0.981$ & $3.4 \pm 1.277$ & -1.657 & -0.643 & 0.000 \\
14 & $2.7 \pm 1.203$ & $3.625 \pm 1.125$ & -1.443 & -0.407 & 0.001 \\
16 & $3.05 \pm 1.085$ & $3.575 \pm 1.059$ & -1.002 & -0.048 & 0.032 \\
20 & $3.4 \pm 0.900$ & $3.2 \pm 0.883$ & -0.197 & 0.597 & 0.319 \\
24 & $3.275 \pm 0.847$ & $3.075 \pm 0.764$ & -0.159 & 0.559 & 0.271 \\
\hline
\end{tabular}

Abbreviation: $\mathrm{Cl}$, confidence interval.

Table 7 Number of Analgesic Pumps Added Within 24 hrs After Surgery (Mean+SD)

\begin{tabular}{|l|l|l|l|l|}
\hline \multicolumn{2}{|l|}{ Group } & \multicolumn{2}{|l|}{$95 \%$ Cl } & P \\
\cline { 1 - 4 } Group RD & Group R & $\begin{array}{l}\text { Lower } \\
\text { Limit }\end{array}$ & $\begin{array}{l}\text { Upper } \\
\text { Limit }\end{array}$ & \\
\hline $\begin{array}{l}1.375 \\
\pm 1.531\end{array}$ & $\begin{array}{l}4.125 \\
\pm 6.022\end{array}$ & -4.706 & -0.794 & 0.008 \\
\hline
\end{tabular}

Abbreviation: SD, Standard deviation.

demand for opioids in the R group was higher than that in the RD group.

\section{Adverse Reactions}

Among the 80 parturients, 51 (26 in the R group,25 in the RD group) had no anal exhaust within $24 \mathrm{hrs}$, and the difference was not statistically significant (Table 8). The incidence of nausea and vomiting, drowsiness, shivering, and facial paresthesia in the two groups was low, but there was no significant difference. One patient in the RD group had symptoms of numbness, palpitations, and chest tightness in the mouth and nose 11 hrs after surgery. Then, the

Table 8 Other Adverse Reactions After Surgery

\begin{tabular}{|l|l|l|l|l|}
\hline \multirow{2}{*}{} & \multicolumn{2}{|l|}{ R (n=40) } & \multicolumn{2}{l|}{ RD (n=40) } \\
\cline { 2 - 5 } & $\begin{array}{l}\text { Number } \\
\text { of Cases }\end{array}$ & $\begin{array}{l}\text { Incidence } \\
\text { Rate }\end{array}$ & $\begin{array}{l}\text { Number } \\
\text { of Cases }\end{array}$ & $\begin{array}{l}\text { Incidence } \\
\text { Rate }\end{array}$ \\
\hline 24h not exhausted & 26 & $65 \%$ & 25 & $62.5 \%$ \\
Nausea, vomiting & 2 & $5 \%$ & 0 & 0 \\
Drowsiness & 1 & $2.5 \%$ & 0 & 0 \\
Shivering & 1 & $2.5 \%$ & 1 & $2.5 \%$ \\
Nasal facial & 0 & 0 & 1 & $2.5 \%$ \\
dysfunction & & & & \\
\hline
\end{tabular}

intravenous analgesia pump was stopped, and the symptoms resolved spontaneously within half an hour after oxygen inhalation. Although low concentrations of LA were used, physiological changes during pregnancy increase sensitivity to LA and might increase the risk of LA systemic toxicity. ${ }^{19-21}$ The instructions for the intravenous analgesic drug butorphanol tartrate $(1 \mathrm{mg} / \mathrm{mL}$, Jiangsu Heng rui Pharmaceutical Co.) clarified that the drug might also cause peripheral nerve paresthesia. We excluded a case of puncture site infection because we observed the puncture point at $24 \mathrm{~h}$ after each patient, there were no cases of redness. ${ }^{22}$

\section{Discussion}

It is known ${ }^{23}$ that women have a higher risk of severe postoperative pain, and severe acute pain, especially after $\mathrm{CD}$, which may lead to CPSP. Although ultrasound-guided TAPB improves the VAS score of the abdominal surgical incision during the local anesthetic efficacy period as well as analgesic satisfaction, the ISP, which is considered a complication of ultrasound-guided TAPB, still causes considerable trouble for patients. This study observed the incidence of ISP during ultrasound-guided TAPB for analgesia after $\mathrm{CD}$ and the effect of additional administration of dexamethasone combined with ropivacaine on the ISP. Among the 80 patients who were ultimately included, 19 women had ISP, 14 cases in the R group and 5 cases in the $\mathrm{RD}$ group. The difference was statistically significant $(\mathrm{P}<0.05)$, which showed that the topical application of dexamethasone could reduce the pain caused by the local anesthetic injection. In this observation of two groups, ISP-positive women had a higher mean value of drug administration than ISP-negative women, but the difference was not statistically significant. Whether ISP increases the demand for intravenous opioids remains to be explored. The postoperative resting VAS scores of the two groups were significantly different at $2 \mathrm{~h}, 10 \mathrm{~h}, 12 \mathrm{~h}$, $14 \mathrm{~h}, 16 \mathrm{~h}$, and the RD group obtained a relatively lower score than the $\mathrm{R}$ group. At the same time, the number of analgesic pump presses in the $\mathrm{RD}$ group was also relatively lower $(\mathrm{R}=4.125 \pm 6.022$ times: $\mathrm{RD}=1.375 \pm 1.530$ times), and the demand for opioids in the $\mathrm{RD}$ group decreased.

The ISP represents a topic that was widely studied in previous years. ${ }^{24}$ Pain is mediated by nerve fibers called nociceptors, which are widely distributed in the skin, muscles, joints and internal organs. The effect of injection volume on pain at the injection site depends on the tissue's 
ability to disperse the drug after receiving a large dose of local anesthetic. This is one of the reasons why injection speed, injection volume, or site appear in some way to affect injection pain. The stretch of tissue caused by the drug causes the nociceptor to discharge and reach its maximum when the tissue is torn. Hypertonic drugs can directly damage nerves, hypotonic fluids can cause water to enter cells, and the swelling of nociceptive neuronal membranes may mimic strong mechanical forces. Tissue damage causes a large number of pro-inflammatory mediators (e.g., bradykinin, serotonin, and prostaglandin) to activate chemical nociceptors. The combination of chemical agents causes ion currents to excite nociceptors, causing immediate pain, and may induce local and distal events, leading to long-term "pain" or paresthesia. ${ }^{25}$ In addition, when the vascular supply is lost or reduced due to trauma, tissue acidity increases. A change in $\mathrm{pH}$ in the environment will open proton-sensitive channels and effectively activate nociceptors. ${ }^{26}$ Hyaluronic acid (HA) is present in fascial fibrous tissue, provides lubrication for muscle smoothness, protects muscles and provides damage repair. ${ }^{27,28}$ Changes in the HA matrix can cause pain, inflammation, and loss of function. ${ }^{29}$

In TAPB, a large dose of local anesthetic under ultrasound stretches the muscles and tears the fascia of the transversus abdominus fascia, forming a clear "fussy shadow". Blood vessels, mechanical damage, large increases in inflammatory mediators, and changes in $\mathrm{pH}$ all activate nociceptors, leading to acute pain or long-term effects. Studies have shown that in patients with subcutaneous injection stimulating pain, VAS scores can reach more than 7 points. $^{30}$ In this study, a significant proportion of patients with positive pain at the injection site experienced moderate or higher pain. In addition to acute pain, deep fascia lesions might also trigger pain sensitivity and CPSP. ${ }^{31}$ Hyperalgesia might result in an undesired higher consumption of opioids, which is secondary to "rebound pain". Rebound pain has been reported in knee reconstruction with femoral nerve block, ${ }^{32}$ and ropivacaine peripheral blockade in rats further confirmed this result. ${ }^{33}$ After the perineural block subsides, the patient might need to take a higher dose of opioids to "catch up" to the treatment level.

Compared with the ropivacaine alone group, the addition of $5 \mathrm{mg}$ of dexamethasone improved the ISP $(\mathrm{P}<0.05)$, and was considered safe and effective. ${ }^{34}$ There are many possible explanations for the mechanism by which dexamethasone improves the ISP. Hong et $\mathrm{al}^{35}$ demonstrated that systemic use of dexamethasone inhibited neuropeptide immune responses in normal nerves. Topically applied, dexamethasone could reduce normal local blood flow, but the degree of reduction was lower than the threshold of ischemic neurostructural changes. ${ }^{36}$ In addition, dexamethasone might also contact local blood vessels to reduce local inflammatory mediators. Devor et $\mathrm{al}^{37}$ confirmed that dexamethasone could directly inhibit the spontaneous ectopic discharge of damaged nerve endings from relieving pain. The effect of dexamethasone on improving ISP via TABP might occur due to a combination of inhibition of systemic inflammation and inhibition of local ectopic discharge. Consistent with previous studies, ${ }^{15}$ dexamethasone as an adjuvant to ropivacaine hydrochloride prolonged the blocking time of ropivacaine. It is generally believed that dexamethasone might delay the absorption of LA by contacting local blood vessels. ${ }^{38}$ Other studies ${ }^{39}$ have shown that the topical application of corticosteroids has a direct inhibitory effect on thin non-myelinating nociceptive $\mathrm{C}$-fiber transmission. Steroids can prolong and enhance the analgesic effect when added as adjuvants during regional blockade, but the results can vary depending on the dose of dexamethasone, the local anesthetic, its concentration, and the site of the block. ${ }^{40,41}$

Pain after CD results in very negative feelings, including incisions and contractions. Unfortunately, we have not found relevant studies that distinguish between incisional pain and injection site pain. Generally, the distinction between pain at the injection site and incisional pain is complicated. In this study, the surgical incision pain and organ pain caused by turning over every half hour might mask the injection site pain, or the patients could not clearly distinguish the pain position from causing a false negative or false positive. However, there is a large distance between the injection site of the TAP and the midumbilical incision of the cesarean section. We tried to determine the position and nature of the pain by gently pressing the injection site. Especially, when the mother indicated pain at the injection site, we confirmed whether the pain was real by gently pressing the area, and judged the location and depth of the pain. We think that gently pressure may be a good way to identify where the pain is. We only observed the occurrence of injection site pain within 24 hrs without further recovery from the return of positive pain in the patient. Most patients with $\mathrm{CD}$ in the medical institution were discharged on the third day after the operation, and soreness may have continued to affect patients. More research is needed for the follow-up of patient prognosis. 


\section{Conclusion}

Dexamethasone as an adjuvant for ropivacaine could effectively relieve the ISP via ultrasound-guided TAPB after CD and could enhance the analgesic effect of ropivacaine.

\section{Author Contributions}

Hai-Lin Liu and Rui-Hao Zhou should be considered cofirst authors. Conceptualization and methodology, LHL and RHZ; Acquisition of data, LHL, LLL, and XY; Analysis and interpretation of data, LHL, RHZ, LLL, XY, LY and HGL; Drafting the article:LHL, RHZ, LLL and XY; Revising it critically for important intellectual content, LY and HGL; Final approval of the version to be published, LHL, RHZ, LLL, XY, LY and HGL; Agreement to be accountable for all aspects of the work, LHL, RHZ, LLL, XY, LY and HGL; Supervision, LY and HGL; Project Administration and funding Acquisition: HGL. All authors contributed to data analysis, drafting or revising the article, gave final approval of the version to be published, and agree to be accountable for all aspects of the work.

\section{Disclosure}

The authors declare that they have no competing interests.

\section{References}

1. ACOG committee opinion \#295: pain relief during labor. Obstet Gynecol. 2004;104(1):213. doi:10.1097/00006250-200407000-00061

2. Eisenach JC, Pan PH, Smiley R, et al. Severity of acute pain after childbirth, but not type of delivery, predicts persistent pain and postpartum depression. Pain. 2008;140(1):87-94. doi:10.1016/j. pain.2008.07.011

3. Lumbiganon P, Laopaiboon M, Gülmezoglu AM, et al. Method of delivery and pregnancy outcomes in Asia: the WHO global survey on maternal and perinatal health 2007-08. Lancet. 2010;375 (9713):490-499. doi:10.1016/S0140-6736(09)61870-5

4. Duarte LT, Fernandes CM, Fernandes MJ, Saraiva RA. Continuous epidural analgesia: analysis of efficacy, side effects and risk factors. Rev Bras Anestesiol. 2004;54(3):371-390. doi:10.1590/S003470942004000300010

5. McDonnell JG, O'donnell BD, Farrell T, et al. Transversus abdominis plane block: a cadaveric and radiological evaluation. Reg Anesth Pain Med. 2007;32(5):399-404. doi:10.1016/j.rapm.2007.03.011

6. Kagwa S, Hoeft MA, Firth PG, et al. Ultrasound guided transversus abdominis plane versus sham blocks after caesarean section in an Ugandan village hospital: a prospective, randomised, double-blinded, single-centre study. Lancet. 2015;385(Suppl 2):S36. doi:10.1016/ S0140-6736(15)60831-5

7. Belavy D, Cowlishaw PJ, Howes M, et al. Ultrasound-guided transversus abdominis plane block for analgesia after caesarean delivery. $\mathrm{Br}$ J Anaesth. 2009;103(5):726-730. doi:10.1093/bja/aep235

8. Naidu RK, Richebe P. Probable local anesthetic systemic toxicity in a postpartum patient with acute fatty liver of pregnancy after a transversus abdominis plane block. A a Case Rep. 2013;1 (5):72-74. doi:10.1097/ACC.0b013e3182973a2f
9. Wong CA. Editorial comment: cardiac arrest from local anesthetic toxicity after a field block and transversus abdominis plane block: a consequence of miscommunication between the anesthesiologist and surgeon and probable local anesthetic systemic toxicity in a postpartum patient with acute fatty liver of pregnancy after a transversus abdominis plane block. A A Case Rep. 2013;1 (5):77-78. doi:10.1097/ACC.0b013e3182a 88776

10. Corvetto MA, Altermatt FR. Improving transversus abdominis plane block safety. Reg Anesth Pain Med. 2014;39(5):440-441. doi:10.1097/AAP.0000000000000134

11. Palte HD. Raising a red flag over TAP blocks. Reg Anesth Pain Med. 2014;39(4):355-356. doi:10.1097/AAP.0000000000000115

12. Weiss E, Jolly C, Dumoulin J-L, et al. Convulsions in 2 patients after bilateral ultrasound-guided transversus abdominis plane blocks for cesarean analgesia. Reg Anesth Pain Med. 2014;39(3):248-251. doi:10.1097/AAP.0000000000000088

13. Yimer $\mathrm{H}$, Woldie $\mathrm{H}$. Incidence and associated factors of chronic pain after caesarean section: a systematic review. J Obstet Gynaecol Can. 2019;41(6):840-854. doi:10.1016/j.jogc.2018.04.006

14. De la Fuente N, Altermatt FR. Adding dexamethasone to peripheral nerve blocks can give better postoperative analgesia. $\mathrm{Br} J$ Anaesth. 2012;108(1):161; author reply 161-2. doi:10.1093/bja/aer426

15. Chen Q, An R, Zhou J, Yang B. Clinical analgesic efficacy of dexamethasone as a local anesthetic adjuvant for transversus abdominis plane (TAP) block: a meta-analysis. PLoS One. 2018;13(6):e0198923.

16. Zhang D, Zhou C, Wei D, et al. Dexamethasone added to local anesthetics in ultrasound-guided transversus abdominis plain (TAP) block for analgesia after abdominal surgery: a systematic review and meta-analysis of randomized controlled trials. PLoS One. 2019;14(1): e0209646. doi:10.1371/journal.pone.0209646

17. Gal RL, Vedula SS, Beck R. Corticosteroids for treating optic neuritis. Cochrane Database Syst Rev. 2015;8:Cd001430.

18. de la Oliva N, Del Valle J, Delgado-Martinez I, et al. Long-term functionality of transversal intraneural electrodes is improved by dexamethasone treatment. IEEE Trans Neural Syst Rehabil Eng. 2019. doi:10.1109/TNSRE.2019.2897256

19. Griffiths JD, Barron FA, Grant S, et al. Plasma ropivacaine concentrations after ultrasound-guided transversus abdominis plane block. Br J Anaesth. 2010;105(6):853-856. doi:10.1093/bja/aeq255

20. Landy C, Gagnon N, Boulland P, et al. Seizures associated with local anaesthetic intoxication. Br J Anaesth. 2012;109(3):463-4; author reply 464 . doi:10.1093/bja/aes286

21. Onishi Y, Kato R, Okutomi T, et al. Transversus abdominis plane block provides postoperative analgesic effects after cesarean section: additional analgesia to epidural morphine alone. J Obstet Gynaecol Res. 2013;39(9):1397-1405. doi:10.1111/jog.2013.39.issue-9

22. Pintaric TS, Cvetko E, Strbenc M, et al. Intraneural and perineural inflammatory changes in piglets after injection of ultrasound gel, endotoxin, $0.9 \% \mathrm{NaCl}$, or needle insertion without injection. Anesth Analg. 2014;118(4):869-873. doi:10.1213/ANE.0000000000000142

23. Joseph KS, Young DC, Dodds L, et al. Changes in maternal characteristics and obstetric practice and recent increases in primary cesarean delivery. Obstet Gynecol. 2003;102(4):791-800. doi:10.1016/s0029-7844(03)00620-3

24. Brazeau GA, Cooper B, Svetic KA, et al. Current perspectives on pain upon injection of drugs. J Pharm Sci. 1998;87(6):667-677. doi: $10.1021 /$ js 9703151

25. Rang HP, Bevan S, Dray A. Chemical activation of nociceptive peripheral neurones. Br Med Bull. 1991;47(3):534-548. doi:10. 1093/oxfordjournals.bmb.a072491

26. Bevan S, Geppetti P. Protons: small stimulants of capsaicin-sensitive sensory nerves. Trends Neurosci. 1994;17(12):509-512. doi:10.1016/ 0166-2236(94)90149-X

27. Jiang D, Liang J, Noble PW. Hyaluronan in tissue injury and repair. Annu Rev Cell Dev Biol. 2007;23(1):435-461. doi:10.1146/annurev. cellbio.23.090506.123337 
28. Baboolal TG, Mastbergen SC, Jones E, et al. Synovial fluid hyaluronan mediates MSC attachment to cartilage, a potential novel mechanism contributing to cartilage repair in osteoarthritis using knee joint distraction. Ann Rheum Dis. 2016;75(5):908-915. doi:10.1136/annrheumdis-2014-206847

29. Salwowska NM, Bebenek KA, Żądło DA, et al. Physiochemical properties and application of hyaluronic acid: a systematic review. J Cosmet Dermatol. 2016;15(4):520-526. doi:10.1111/jocd.2016.15. issue-4

30. Yoshida T, Otaki Y, Katsuyama N, et al. New adalimumab formulation associated with less injection site pain and improved motivation for treatment. Mod Rheumatol. 2019;29(6):949-953. doi:10.1080/ 14397595.2018.1520426

31. Yazici Yilmaz F, Aydogan Mathyk B, Yildiz S, Yenigul NN, Saglam C. Postoperative pain and neuropathy after caesarean operation featuring blunt or sharp opening of the fascia: a randomised, parallel group, double-blind study. J Obstet Gynaecol. 2018;38 (7):933-939. doi:10.1080/01443615.2018.1437125

32. Williams BA, Bottegal MT, Kentor ML, et al. Rebound pain scores as a function of femoral nerve block duration after anterior cruciate ligament reconstruction: retrospective analysis of a prospective, randomized clinical trial. Reg Anesth Pain Med. 2007;32(3):186-192. doi:10.1016/j.rapm.2006.10.011

33. Kolarczyk LM, Williams BA. Transient heat hyperalgesia during resolution of ropivacaine sciatic nerve block in the rat. Reg Anesth Pain Med. 2011;36(3):220-224. doi:10.1097/AAP.0b013e318217 $6 \mathrm{f5a}$
34. Knight JB, Schott NJ, Kentor ML, et al. Neurotoxicity of common peripheral nerve block adjuvants. Curr Opin Anaesthesiol. 2015;28 (5):598-604. doi:10.1097/ACO.0000000000000222

35. Hong D, Byers MR, Oswald RJ. Dexamethasone treatment reduces sensory neuropeptides and nerve sprouting reactions in injured teeth. Pain. 1993;55(2):171-181. doi:10.1016/0304-3959(93)90146-G

36. Shishido H, Kikuchi S, Heckman H, et al. Dexamethasone decreases blood flow in normal nerves and dorsal root ganglia. Spine (Phila Pa 1976). 2002;27(6):581-586. doi:10.1097/00007632-20020315000005

37. Devor M, Govrin-lippmann R, Raber P. Corticosteroids suppress ectopic neural discharge originating in experimental neuromas. Pain. 1985;22(2):127-137. doi:10.1016/0304-3959(85)90173-3

38. Marks R, Barlow JW, Funder JW. Steroid-induced vasoconstriction: glucocorticoid antagonist studies. J Clin Endocrinol Metab. 1982;54 (5):1075-1077. doi:10.1210/jcem-54-5-1075

39. Johansson A, Hao J, Sjolund B. Local corticosteroid application blocks transmission in normal nociceptive C-fibres. Acta Anaesthesiol Scand. 1990;34(5):335-338. doi:10.1111/aas.1990.34. issue-5

40. Pehora C, Pearson AM, Kaushal A, Crawford MW, Johnston B. Dexamethasone as an adjuvant to peripheral nerve block. Cochrane Database Syst Rev. 2017;11:Cd011770.

41. Marhofer P, Columb M, Hopkins PM, et al. Dexamethasone as an adjuvant for peripheral nerve blockade: a randomised, triple-blinded crossover study in volunteers. Br J Anaesth. 2019;122(4):525-531. doi:10.1016/j.bja.2019.01.004
Journal of Pain Research

\section{Publish your work in this journal}

The Journal of Pain Research is an international, peer reviewed, open access, online journal that welcomes laboratory and clinical findings in the fields of pain research and the prevention and management of pain. Original research, reviews, symposium reports, hypothesis formation and commentaries are all considered for publication. The manuscript management system is completely online and includes a very quick and fair peer-review system, which is all easy to use. Visit http:// www.dovepress.com/testimonials.php to read real quotes from published authors. 